\title{
The Effect of Silver, Zinc Oxide, and Titanium Dioxide Nanoparticles Used as Final Irrigation Solutions on the Fracture Resistance of Root-Filled Teeth
}

This article was published in the following Dove Press journal:

Clinical, Cosmetic and Investigational Dentistry

\author{
Zahra Jowkar (D) \\ Seyed Ahmadreza Hamidi iD ${ }^{2}$ \\ Fereshteh Shafiei ${ }^{1}$ \\ Yasamin Ghahramani ${ }^{3}$ \\ 'Oral and Dental Disease Research \\ Center, Department of Operative \\ Dentistry, School of Dentistry, Shiraz \\ University of Medical Sciences, Shiraz, \\ Iran; ${ }^{2}$ Department of Operative \\ Dentistry, School of Dentistry, Shiraz \\ University of Medical Sciences, Shiraz, \\ Iran; ${ }^{3}$ Department of Endodontics, \\ School of Dentistry, Shiraz University of \\ Medical Sciences, Shiraz, Iran
}

\begin{abstract}
Aim: This study was conducted to evaluate the effect of three nanoparticle solutions used as final root canal irrigants on the fracture resistance of endodontically treated roots.

Materials and Methods: Sixty intact single-rooted premolar teeth were used after removing the crowns below the cementum-enamel junction to standardize the length of the remaining roots to $13 \mathrm{~mm}$. After instrumenting the roots using ProTaper Universal rotary instruments up to size F4, the roots were randomly divided into six groups $(n=10)$ according to the final irrigating solutions: Group 1: normal saline; Group 2: 2\% chlorhexidine (CHX); Group 3: $17 \%$ EDTA $+2.5 \% \mathrm{NaOCl}$; Group 4: $17 \%$ EDTA $+0.1 \%$ silver nanoparticle (SNP) solution; Group 5: 17\% EDTA+0.1\% titanium dioxide nanoparticle (TNP) solution; Group 6: $17 \%$ EDTA $+0.1 \%$ zinc oxide nanoparticle (ZNP) solution. After filling the root canals with gutta-percha and AH Plus sealer, the fracture resistance (FR) values were measured. The data were subjected to the one-way analysis of variance and the Tamhane post hoc test $(\mathrm{p}=0.05)$. Results: EDTA + NaOCl had the lowest FR value, followed by normal saline and CHX (p values $<0.05$ ). No significant difference was found between the FR of roots irrigated with $\mathrm{CHX}$ and normal saline $(\mathrm{p}>0.05)$. The application of nanoparticles (SNP, TNP, and ZNP) was associated with a significantly greater FR than that of other irrigation solutions ( $\mathrm{p}$ values $<0.05$ ). Conclusion: The final irrigation of root canals with nanoparticles enhanced the fracture resistance of the endodontically treated roots. The lowest FR value was observed for $\mathrm{NaOCl}$.

Keywords: fracture resistance, nanoparticles, root canal irrigants
\end{abstract}

\section{Introduction}

Chemomechanical preparation during endodontic treatment weakens the tooth structure and decreases its fracture strength. ${ }^{1}$ The quality of adhesion and the mechanical interlocking between the root canal dentin and the filling material can positively affect the fracture strength of endodontically treated teeth. ${ }^{1,2}$ Guttapercha used with an insoluble root canal sealer has been universally regarded as the gold standard for root canal filling materials. However, the ability of guttapercha used with a sealer to reinforce the fracture resistance of an endodontically treated root is still controversial. ${ }^{2,3}$ It has been suggested that using adhesive sealers in the root canal system enhances the fracture resistance of root-filled teeth. ${ }^{2}$

Root canal irrigation solutions have been employed along with mechanical instrumentations to eliminate the pulp remnants and the smear layer formed after preparing the root canal. Irrigation solutions can also open the dentinal tubules to clean the root canal space adequately and therefore resulting in better conditions for subsequent canal
Correspondence: Fereshteh Shafie Tel +98 71-36263193

Email shafief@sums.ac.ir 
obturation and adhesion. Moreover, smear layer removal from the root canal may improve the contact of root canal filling materials and root canal sealers with the canal walls and thus may improve the penetration of sealers into the dentinal tubules. ${ }^{4}$ However, some irrigation solutions might negatively affect the bond strength of resinous materials to root dentin. ${ }^{5}$ It has been reported that the chemical properties and concentration of irrigants may affect some physical properties of root canal dentin such as microhardness and flexural strength. ${ }^{5-7}$ After the application of the irrigation solution, the chemically altered dentin may has such problems as dentinal cracks and vertical root fracture. ${ }^{1}$ Final irrigation solutions can alter the wetting of root canal dentin by sealers which may possibly influence the bond strength of root canal filling materials to root canal dentin. ${ }^{4}$ It has recently been reported that final irrigation regimens have an impact on the fracture resistance of the teeth. ${ }^{1}$ The chemical interactions between different irrigants during root canal treatment and the subsequent cumulative effects on the root dentin have also been assumed. ${ }^{8}$

The bacteria might still be present within the dentinal tubules even after root canal cleaning and shaping and might be inaccessible to the currently used irrigants or medicaments due to their limited penetrability into the dentinal tubules. ${ }^{9}$ Besides, bacterial biofilm has demonstrated some degree of resistance to common root canal irrigation solutions such as sodium-hypochlorite and chlorhexidine. ${ }^{9}$ Therefore, some attempts have been made to introduce novel antimicrobial solutions as root canal irrigants.

Various irrigation solutions have been used for final irrigation purposes in endodontic practice such as sodium hypochlorite $(\mathrm{NaOCl})$, chlorhexidine $(\mathrm{CHX})$, and ethylenediamine tetraacetic acid (EDTA). ${ }^{1}$ One of the most common irrigation solutions used by endodontists is sodium hypochlorite $(\mathrm{NaOCl})$ because of its ability to solubilize tissues, its antimicrobial effect, and its ability to dissolve biofilms. ${ }^{10}$ However, some important drawbacks of $\mathrm{NaOCl}$ are its unpleasant smell and negative effect on the penetration of the resin sealer into dentin and its polymerization. ${ }^{10,11}$ Additionally, $\mathrm{NaOCl}$ is a deproteinizing agent that dissolves collagen and degenerates dentin. ${ }^{11}$ In a previous study, the mechanical properties of root dentin such as flexural strength, ultimate tensile strength, and fracture resistance were significantly reduced after $\mathrm{NaOCl}$ application. ${ }^{12}$ It has been previously reported that $\mathrm{NaOCl}$ solutions could reduce the fracture resistance of root canal-treated bovine teeth by about $30 \%{ }^{13}$

$\mathrm{CHX}$ has been recommended as a final irrigation solution because of its wide range of antimicrobial activity, inhibitory effect on matrix metalloproteinase, low cytotoxicity, and substantivity. ${ }^{14}$ Furthermore, when used as a final irrigant after EDTA/NaOCl irrigation, $\mathrm{CHX}$ was able to enhance the fracture resistance of root-filled teeth with AH Plus in a previous study. ${ }^{15} \mathrm{CHX}$ can also decrease the contact angle of root canal sealers and thus increase wettability. $^{16}$

Recently, metal nanoparticles (NPs) have gained more attention in dentistry especially because of their antibacterial properties. NPs have been shown to have a high degree of interaction with the bacterial cell wall because of their high surface area and small size. ${ }^{17}$ Even in a remarkably lower concentration, silver nanoparticles (SNPs) have demonstrated the same bactericidal effect as $5.25 \% \mathrm{NaOCl}$ against Enterococcus faecalis. ${ }^{18}$ Therefore, SNPs have been proposed as a novel non-toxic endodontic irrigant. ${ }^{19}$ The significant antibacterial efficacy of zinc oxide nanoparticles (ZNPs) against planktonic Enterococcus faecalis has been previously demonstrated. ${ }^{17}$ Recently, titanium dioxide nanoparticles (TNPs) have also been used in dentistry as an antibacterial agent. TNPs have higher antibacterial properties than chlorhexidine, possess a pleasing color, and have a high biocompatibility. $^{20,21}$

No previous study has been conducted on the efficacy of SNPs, TNPs, and ZNPs used as novel root canal irrigants on the fracture resistance of endodontically treated teeth. Therefore, the aim of the present study was to assess the effect of three nanoparticle solutions used as final root canal irrigants on the fracture resistance of roots filled with gutta-percha and AH Plus sealer (Dentsply De Trey Gmbh, Konstanz, Germany).

\section{Materials and Methods}

The study protocol was approved by the Research and Ethics Committee of Shiraz University of Medical Sciences (Protocol \# IR.SUMS.DENTAl.REC.1398.75). The patients whose extracted teeth were used for this research provided written informed consent. All of the procedures of this experimental study were performed by a blinded calibrated operator. Sixty intact single-rooted human mandibular premolar teeth (with the buccolingual dimension at the cementoenamel junction (CEJ) of $5.1 \pm 0.5 \mathrm{~mm}$ and the mesiodistal dimension of $4.4 \pm 0.5 \mathrm{~mm}$ ) which were extracted for orthodontic or periodontal reasons were collected for this study and were stored in a $0.5 \%$ chloramine solution at $4{ }^{\circ} \mathrm{C}$ for a period of no longer than one month after extraction until use. The teeth were sectioned below the CEJ perpendicular to the long axis of the roots so that the crowns were removed 
and the remaining length of the roots was $13 \pm 1 \mathrm{~mm}$. The root canals of all the specimens were instrumented with the ProTaper NiTi rotary system (Dentsply Maillefer, Ballaigues, Switzerland) up to size F4. The working length of each sectioned root was considered to be $1 \mathrm{~mm}$ shorter than the root length. After using each file, $1 \mathrm{~mL} 2.5 \% \mathrm{NaOCl}$ (SigmaAldrich, St. Louis, MO, USA) via a $27-\mathrm{G}$ irrigating tip (Endo-Eze; Ultradent, South Jordan, UT) was used for root canal irrigation. The outward flow of irrigant from the apices was prevented by sealing the apices of the roots with wax. Following the completion of root canal instrumentation, all the samples were irrigated with $5 \mathrm{~mL} 2.5 \% \mathrm{NaOCl}$ and $2 \mathrm{~mL}$ saline. The sectioned roots were randomly divided into six experimental groups $(n=10)$ based on the final sequence of irrigation:

Group 1: normal saline ( $5 \mathrm{~mL}, 1$ minute)

Group2: 17\% EDTA (5 mL, $1 \mathrm{~min}$ ) and 2\% chlorhexidine (Consepsis, Ultradent Inc., South Jordan, UT, USA) (5 mL, 1 minute)

Group 3: 17\% EDTA (5 mL, $1 \mathrm{~min})$ and $2.5 \% \mathrm{NaOCl}$ (5 mL, $1 \mathrm{~min})$

Group 4: 17\% EDTA (5 mL, $1 \mathrm{~min})$ and $0.1 \% \mathrm{SNP}$ solution ( $5 \mathrm{~mL}, 1 \mathrm{~min})$

Group 5: 17\% EDTA (5 mL, $1 \mathrm{~min})$ and 0.1\% TNP solution ( $5 \mathrm{~mL}, 1 \mathrm{~min})$

Group 6: 17\% EDTA (5 mL, $1 \mathrm{~min})$ and $0.1 \% \mathrm{ZNP}$ solution ( $5 \mathrm{~mL}, 1 \mathrm{~min})$

The particle sizes of the SNPs, ZNPs, and TNPs (purchased from ASEPE Company, Tabriz, Iran) were $20 \mathrm{~nm}$, $<50 \mathrm{~nm}$, and $20 \mathrm{~nm}$, respectively. EDTA was applied in all experimental groups except group 1 (normal saline).

Each root canal was rinsed with $5 \mathrm{~mL}$ of distilled water to remove any residual irrigation solution after the application of the final irrigant solution. After drying the root canals with paper points, the roots were filled with ProTaper F4 guttapercha (Dentsply Maillefer, Ballaigues, Switzerland) and $\mathrm{AH}$ Plus root canal sealer (Dentsply DeTrey, Konstanz, Germany) using a single-cone technique. The obturation quality of the root canals was checked using periapical radiographs. After being wrapped in moist gauze, the specimens were stored in separate jars in a $37^{\circ} \mathrm{C}$ incubator for 1 week to allow the proper setting of the sealer. To simulate the periodontal ligament, the surfaces of the roots were coated with a silicone material with a uniform thickness $(2 \mathrm{~mm})$ (C-silicone, Zetalabor, Zhermack SpA, Badia Polesine, Italy) up to $2 \mathrm{~mm}$ apical to the CEJ. The roots were embedded in self-curing acrylic resin (Acropars, Marlik Co., Tehran, Iran) covering the apical $10 \mathrm{~mm}$ of each root. After attaching the acrylic blocks to the lower plate of a universal testing machine (Instron Z020, Zwick Roell, Ulm, Germany), a steel ball with a spherical tip (5 $\mathrm{mm}$ in diameter) was mounted on the upper plate and was placed over the center of the root canal orifice to apply a compressive load at a speed of $1 \mathrm{~mm} / \mathrm{min}$ to the root parallel to its long axis until fracture. The force required to fracture each root was recorded in Newtons $(\mathrm{N})$. The fracture pattern of the roots was examined using a $4 \times$ magnifying glass. The schematic representation of the specimen preparation procedures has been shown in Figure 1.

The normality of the data was checked using the Kolmogorov-Smirnov test. The one-way analysis of variance (one-way ANOVA), followed by the Tamhane post hoc test, was used for data analysis. All the analyses were conducted using SPSS software version 17 (SPSS Inc, Chicago, USA). The statistical comparisons were considered significant at $\mathrm{p}$ values less than 0.05 .

\section{Results}

The mean fracture resistance (FR) values and standard deviations (SD) in $\mathrm{N}$ are shown in Table 1. The one-way ANOVA test showed a significant difference among all groups $(\mathrm{P}<0.05)$. The Tamhane post hoc test was performed for pair-wise comparisons. Group 3 (EDTA + $\mathrm{NaOCl})$ had the lowest FR value $(636.90 \mathrm{~N})$, followed by group 1 (normal saline, $871.60 \mathrm{~N}$ ), and group 2 $(\mathrm{CHX}, 861.20)$ ( $\mathrm{p}$ values $<0.05)$. No significant difference was found between the FR of roots irrigated with $\mathrm{CHX}$ and normal saline $(\mathrm{p}>0.05)$. The applications of nanoparticles (SNP, TNP, and ZNP) were associated with significantly greater FR of roots compared to that of other irrigation solutions ( $\mathrm{p}$ values $<0.05$ ). No significant differences in FR values were noted among groups 4 (EDTA + SNP), 5 (EDTA + TNP), and 6 (EDTA + ZNP) (p values $>$ 0.05). Regardless of the final irrigant, the examination of the fracture pattern of the roots revealed that the majority of the samples fractured in a labiolingual direction.

\section{Discussion}

This study was conducted to evaluate the effect of different final irrigation solutions on the FR of endodontically treated roots filled with gutta-percha and $\mathrm{AH}$ Plus. According to the results of the present study, the three groups finally irrigated with nanoparticles (SNPs, TNPs, and ZNPs) demonstrated greater FR compared to those irrigated with normal saline, $\mathrm{CHX}$, or $\mathrm{NaOCl}$. The lowest mean of FR value was observed in the group treated with $\mathrm{NaOCl}$. 


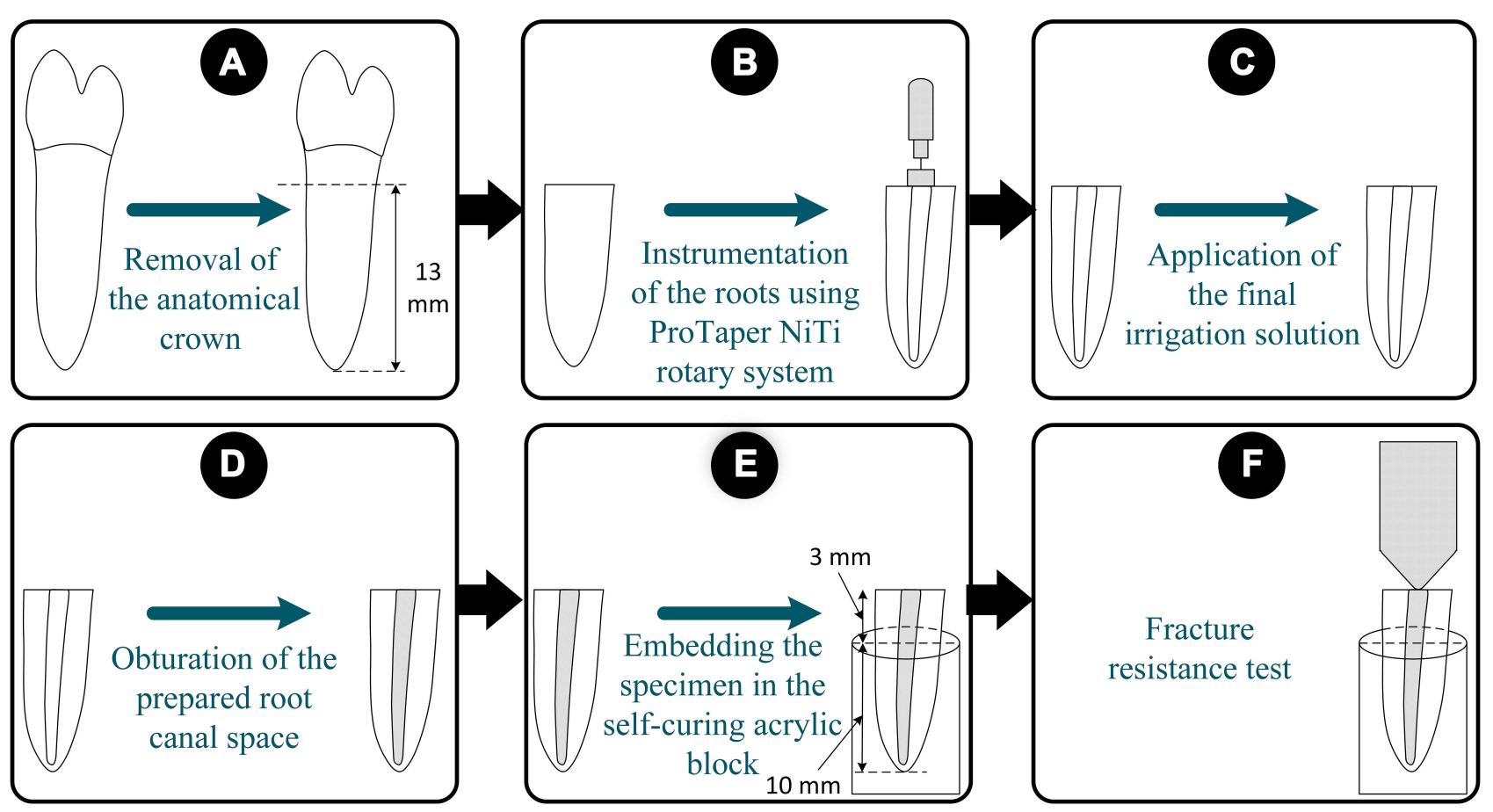

Figure I The schematic representation of the specimen preparation procedures. (A) The crown of a premolar tooth was sectioned and removed. (B) The instrumentation of the root was performed using the ProTaper NiTi rotary system. (C) The final irrigation protocol was performed according to the experimental group. (D) The root was obturated. (E) The roots were embedded in the self-curing acrylic resin block. (F) The fracture resistance was measured.

$\mathrm{NaOCl}, \mathrm{CHX}$, and EDTA are the most common endodontic irrigants. ${ }^{22}$ Therefore, the effects of the nanoparticles on the FR of endodontically treated roots were compared to those of normal saline, $\mathrm{CHX}$, and $\mathrm{NaOCl}$ in this study. One of the root canal irrigants used in this study was $\mathrm{NaOCl}$. It is an antimicrobial agent with the ability to dissolve biofilms. However, $\mathrm{NaOCl}$ is incapable of removing the smear layer and inorganic residues. ${ }^{10,12}$ Therefore, the application of a chelating agent such as EDTA is recommended..$^{10}$ Moreover, the organic substances in the root canal might easily inactivate $\mathrm{NaOCl}$. The ability of

Table I The Mean Fracture Resistance Values \pm Standard Deviations $(\mathrm{N})$ of the Experimental Groups

\begin{tabular}{|l|l|l|}
\hline Group & Final Irrigation Procedures & Fracture Resistance \\
\hline 1 & Normal saline (control) & $871.60 \pm 52^{\mathrm{a}}$ \\
2 & $\mathrm{CHX}$ & $861.20 \pm 91^{\mathrm{a}}$ \\
3 & EDTA + NaOCl & $636.90 \pm 89^{\mathrm{b}}$ \\
4 & EDTA + SNP & $1146.50 \pm 81^{\mathrm{c}}$ \\
5 & EDTA + TNP & $1276.70 \pm 193^{\mathrm{c}}$ \\
6 & EDTA + ZNP & $1055.90 \pm 112^{\mathrm{c}}$ \\
\hline
\end{tabular}

Note: Different superscripted letters indicate statistically significant differences $(p<0.05)$.

Abbreviations: $\mathrm{CHX}$, chlorhexidine; EDTA, ethylenediamine tetraacetic acid; $\mathrm{NaOCl}$, sodium hypochlorite; SNP, silver nanoparticle; TNP, titanium dioxide nanoparticle; ZNP, zinc oxide nanoparticle.
$\mathrm{NaOCl}$ for the effective disinfection of difficult-to-reach areas is also questionable. ${ }^{23}$ In this study, the lowest fracture value was observed for the roots finally irrigated with $\mathrm{NaOCl}$. This result is in line with a previous study which showed that $\mathrm{NaOCl}$ could reduce the FR of root canaltreated bovine teeth by about $30 \% .{ }^{13}$ This undesired root weakening effect can be attributed to the effects of $\mathrm{NaOCl}$ on dentin. The depletion of the dentin components of the organic framework (about $22 \mathrm{wt} \%$ ) can result from the proteolytic action of $\mathrm{NaOCl}$ which has negative impacts on dentin such as weakening the dentin framework and reducing the dry weight by $14 \% .{ }^{12,24}$ Therefore, after the application of $\mathrm{NaOCl}$, physical and mechanical changes in the dentin may occur such as microcrack formation and the reduction of flexural strength, microhardness, and modulus of elasticity. ${ }^{12}$ The reduction of flexural strength and elastic modulus may potentially make dentin more brittle. $^{12}$ An increase in stress concentration, dentin contraction, and crack propagation following the deleterious effects of $\mathrm{NaOCl}$ solutions on the organic framework of dentin might ultimately result in a significant decrease in $\mathrm{FR}^{24}$

In spite of being incapable of removing the smear layer, CHX has been suggested as a final irrigant. ${ }^{25} \mathrm{CHX}$ did not affect the FR of the root-filled teeth in this study 
which is in line with a previous study. ${ }^{1}$ Moreover, the FR of roots which were finally irrigated with $\mathrm{NaOCl}$ was lower than that of those irrigated with CHX. This finding might be related to the negative effect of $\mathrm{NaOCl}$ on the bond strength of resin-based sealers to root dentin and the positive influence of $\mathrm{CHX}$ on the bonding stability of resin-based sealers to root dentin. ${ }^{25}$ Besides, less smear layer is formed after using CHX as a root canal irrigant in comparison with using $\mathrm{NaOCl}^{26}$ It was found in a previous research that the final irrigation with $\mathrm{CHX}$ did not influence the bond strength of gutta-percha/AH Plus to root canal dentin. ${ }^{5}$ Although CHX did not affect the FR of endodontically treated roots in the present study, it could prevent the subsequent possible coronal microleakage due to its substantivity. ${ }^{14}$

Recently, metal NPs have received more attention in dentistry especially due to their antibacterial properties. SNPs, TNPs, and ZNPs have recently been suggested to be used as dentin or enamel surface pretreatments so that their antimicrobial properties can be exploited. ${ }^{27}$ Additionally, no interference with the push-out bond strength of the fiber posts was observed after intraradicular dentin pretreatment with SNPs, TNPs, and ZNPs. ${ }^{28}$ Nanoparticles can also be used as root canal irrigants. ${ }^{19}$ Three nanoparticles (SNPs, TNPs, and ZNPs) were used as final irrigation solutions in this study and the groups treated with them had the highest FR values. No significant differences were found among the fracture resistances of the three nanoparticles used in this study. Compared to CHX, metal nanoparticles can penetrate into the deeper layers of the biofilm due to their small size and can be mechanically trapped in plaques. ${ }^{29}$ SNPs have exhibited long-term broad-spectrum antibacterial properties via sustained silver ion release. ${ }^{30}$ Additionally, the biocompatibility of SNPs has been previously shown. ${ }^{31}$ The bacteriostatic and bactericidal effects of SNPs on five different oral pathogenic bacteria were significantly higher than those of chlorhexidine in a previous study. ${ }^{32}$ When used as intracanal irrigants, silver nanoparticles can eliminate bacteria and bacterial biofilms more efficiently than chlorhexidine. ${ }^{33}$ Another nanoparticle that was used in this study was ZNP. The selective antibacterial effects of ZNPs against several types of gramnegative and gram-positive bacteria with minimal effects on human cells have been previously confirmed. ${ }^{34}$ Additionally, an MMP inhibitory effect has been reported for ZNPs. ${ }^{35}$ Moreover, ZNPs were able to retain their antibacterial properties against Enterococcus faecalis even after aging for 90 days. ${ }^{36}$ The last nanoparticle which was used in this study was TNP. TNPs have demonstrated good antiadhesive properties against Streptococcus mutans and have antibacterial properties by causing the production of free radicals. ${ }^{37}$

One of the main problems of common root canal irrigants is their inability to reach the apical third and the most complex anatomical structures (isthmi and anastomosis). Nanoparticles have small-sized molecules and might have better penetration into these areas. ${ }^{36,38}$

In the present study, EDTA was employed before the application of the nanoparticles. The presence of the smear layer on the root canal walls negatively affected the adaptation, penetration, and bond strength of the sealers. ${ }^{15,39}$ The application of a chelating agent such as EDTA for the removal of the smear layer resulted in improved penetration, retention, and bond strength of the AH Plus sealer. ${ }^{39}$ Therefore, in the present study, EDTA was applied for 1 minute before irrigation with the nanoparticles. Although EDTA has been proposed for final irrigation, it has some limitations such as low antimicrobial activity and changing the mechanical properties of dentin. ${ }^{40,41}$ For these reasons, the application of the nanoparticles used in this study after EDTA can compensate for its limitations. Moreover, demineralized microporous collagen matrices were identified from instrumented canal walls after using $17 \%$ EDTA. $^{41}$ Therefore, the simultaneous removal of smear layers and making dentinal tubules patent without demineralizing dentin is difficult to obtain using common smear layer-removing endodontic irrigants. ${ }^{41}$ The thin layer of demineralized collagen fibrils which may remain on the root canal dentin surface after using EDTA as the final canal irrigant can lead to the poor wettability of root canal sealers after EDTA irrigation. ${ }^{41}$ The reduced surface tension of root canal irrigants by the application of a surfactant has improved their dentin wetting ability. ${ }^{42}$ One possible explanation for the improved FR of the roots irrigated with the nanoparticles may be the probable improved wettability and the increased dentin surface energy possibly due to irrigating the canals with them. However, the effects of nanoparticles on wettability and dentin surface energy were not assessed in this study and should be evaluated in future. On the other hand, nanoscale molecules such as nanofillers from dentin adhesives cannot penetrate into a fully expanded demineralized collagen matrix. ${ }^{43}$ Most endodontic sealers contain macro/ microfillers by classification. Besides, a dried, collapsed, demineralized collagen matrix which remains after the application of EDTA is not appropriate for the infiltration of resin sealer molecules. ${ }^{41}$ The application of nanoparticles after EDTA in this study might have led to 
a better contact of the nanoparticles with a higher surface area of dentin and subsequently the better penetration of the nanoparticle molecules into the demineralized microporous collagen fibers. These explanations might justify the higher FR values obtained for the nanoparticles used as final irrigants compared to the other agents.

In the current study, it was observed that the roots treated with nanoparticles had higher FR than those treated with CHX groups. This effect might be related to the fact that nanoparticles have smaller sizes than the molecules of CHX. Besides, nanoparticle molecules have a large proportion of surface atoms, a high surface energy, and a large surface area. ${ }^{44}$ These properties might affect the penetration of the nanoparticles into the dentinal collagen. This issue should be assessed in future studies.

The bonding of the root canal sealer to the radicular dentin is one of the necessary requirements for increasing the root strength. ${ }^{45}$ It has been demonstrated that root canal irrigants can affect the bond strength of resin sealers such as AH Plus (which was used in this study) to dentin by modifying the surface properties of the root canal dentin or removing the smear layer. ${ }^{5,39}$ Moreover, irrigants may alter the wettability of root canal sealers and possess the ability to clean and demineralize dentin surfaces. ${ }^{39,42}$ It has been previously found that SNP pretreatment before fiber post cementation with resin cements can improve the push-out bond strength of fiber post to root canal dentin. ${ }^{28}$ The effect of the nanoparticles used as root canal irrigants on the bond strength of the resin sealer to radicular dentin was not assessed directly in the present study. However, the high fracture resistance values observed for the groups irrigated with the nanoparticles might be related to the positive effects of the nanoparticles on the sealer bond strength to root dentin. The probable better contact of the sealer to the root canal walls treated with the nanoparticles and its subsequent altered penetration into the dentinal tubules could justify this finding. Besides, nanoparticles might alter the wettability of radicular dentin which should be assessed in future studies.

Generally, the use of nanoparticles as root canal irrigants may have some advantages over common root canal irrigants. The average diameter of dentinal tubules $(1 \mu \mathrm{m})$ is ten times greater than the average diameter of nanoparticles $(0.1 \mu \mathrm{m})$ which leads to the easier penetration of nanoparticles into the tubules and their probable subsequent sustained release and longer antibacterial effects. ${ }^{38}$ Nanoparticles have a bactericidal activity which is inversely related to the nanoparticle size. ${ }^{46}$ Moreover, nanoparticles can inhibit bacterial adherence to the root canal system. ${ }^{17}$

This in vitro study has some limitations. This study was only a preliminary study to assess the effect of nanoparticles used as final irrigants on the fracture resistance of the endodontically treated teeth. EDTA was applied before nanoparticles in this study and further studies are required to assess the effect of the nanoparticles used as final irrigants without applying EDTA to exactly clarify the effect of nanoparticles on the fracture resistance of the endodontically treated roots. The vertical root fracture is a multifactorial problem. Different factors affecting the FR of endodontically treated teeth such as occlusion, residual tooth structure, parafunctional habits, and coronal restoration should also be considered in future studies. ${ }^{47}$ The effects of nanoparticles on the wetting ability of radicular dentin and surface free energy were not assessed in this study. Only one type of sealer was used in the present study. Therefore, further in vitro and in vivo studies are needed to investigate the effects of SNPs, TNPs and ZNPs used as final irrigants on the early and long-term bond strength of the sealer to root canal dentin and the resultant effect on the FR of the roots using various types of resin sealers. Besides, the possible long-term antibacterial properties of nanoparticles in root canals, the possible release of nanoparticles into saliva and oral cavity, and their accumulation in vital organs should be evaluated.

\section{Conclusion}

The final irrigation protocol influenced the FR of endodontically treated roots. The final irrigation of root canals with nanoparticles enhanced the fracture resistance of the endodontically treated roots. The lowest value of FR was observed for $\mathrm{NaOCl}$.

\section{Acknowledgments}

The authors thank the Vice-Chancellery of Research, Shiraz University of Medical Sciences for supporting this research and Biomaterial Research Center of Shiraz University of Medical Sciences for testing the specimens (Number: 98-01-99-20035). The authors thank Dr. Mehrab Sayadi from the Dental Research Development Center for the statistical analyses. The authors also thank Dr. Arash Moradi for editorial assistance.

\section{Disclosure}

The authors report no conflicts of interest in this work. 


\section{References}

1. Uzunoglu E, Yilmaz Z, Erdogan O, Görduysus M. Final irrigation regimens affect fracture resistance values of root-filled teeth. $J$ Endod. 2016;42(3):493-495. doi:10.1016/j.joen.2015.12.006

2. Schäfer E, Zandbiglari T, Schäfer J. Influence of resin-based adhesive root canal fillings on the resistance to fracture of endodontically treated roots: an in vitro preliminary study. Oral Surg Oral Med Oral Pathol Oral Radiol Endod. 2007;103(2):274-279. doi:10.10 16/j.tripleo.2006.06.054

3. Çobankara FK, Üngör M, Belli S. The effect of two different root canal sealers and smear layer on resistance to root fracture. $J$ Endod. 2002;28(8):606-609. doi:10.1097/00004770-200208000-00011

4. Ballal NV, Tweeny A, Khechen K, Prabhu KN, Tay FR. Wettability of root canal sealers on intraradicular dentine treated with different irrigating solutions. $J$ Dent. 2013;41(6):556-560. doi:10.1016/j. jdent.2013.04.005

5. Prado M, Simão RA, Gomes BP. Effect of different irrigation protocols on resin sealer bond strength to dentin. J Endod. 2013;39 (5):689-892. doi:10.1016/j.joen.2012.12.009

6. Oliveira LD, Carvalho CAT, Nunes W, Valera MC, Camargo CHR, Jorge AOC. Effects of chlorhexidine and sodium hypochlorite on the microhardness of root canal dentin. Oral Surg Oral Med Oral Pathol Oral Radiol Endod. 2007;104(4):e125-e128. doi:10.1016/j.tripleo. 2007.04.019

7. Marending M, Paque F, Fischer J, Zehnder M. Impact of irrigant sequence on mechanical properties of human root dentin. $J$ Endod. 2007;33(11):1325-1328. doi:10.1016/j.joen.2007.08.005

8. Hülsmann M. Effects of mechanical instrumentation and chemical irrigation on the root canal dentin and surrounding tissues. Endod Topics. 2013;29(1):55-86. doi:10.1111/etp. 12047

9. Nair P. On the causes of persistent apical periodontitis: a review. Int Endod J. 2006;39(4):249-281. doi:10.1111/j.1365-2591.2006.01099.x

10. Dioguardi M, Di Gioia G, Illuzzi G, Laneve E, Cocco A, Troiano G. Endodontic irrigants: different methods to improve efficacy and related problems. Eur J Dent. 2018;12(03):459-466. doi:10.4103/ ejd.ejd 56_18

11. Rocha $\mathrm{AW}$, de Andrade CD, Leitune VCB, et al. Influence of endodontic irrigants on resin sealer bond strength to radicular dentin. Bull Tokyo Dent Coll. 2012;53(1):1-7. doi:10.2209/tdcpublication.53.1

12. Pascon FM, Kantovitz KR, Sacramento PA, Nobre-dos-Santos M, Puppin-Rontani RM. Effect of sodium hypochlorite on dentine mechanical properties. A review. J Dent. 2009;37(12):903-908. doi:10.1016/j.jdent.2009.07.004

13. Souza EM, Calixto AM, e Lima CN, Pappen FG, De-Deus G. Similar influence of stabilized alkaline and neutral sodium hypochlorite solutions on the fracture resistance of root canal-treated bovine teeth J Endod. 2014;40(10):1600-1603. doi:10.1016/j.joen.2014.02.028

14. Souza M, Cecchin D, Farina AP, et al. Evaluation of chlorhexidine substantivity on human dentin: a chemical analysis. J Endod. 2012;38 (9):1249-1252. doi:10.1016/j.joen.2012.06.003

15. Turk T, Kaval M, Sarikanat M, Hülsmann M. Effect of final irrigation procedures on fracture resistance of root filled teeth: an ex vivo study. Int Endod J. 2017;50(8):799-804. doi:10.1111/iej.12680

16. de Assis DF, Do Prado M, Simão RA. Evaluation of the interaction between endodontic sealers and dentin treated with different irrigant solutions. J Endod. 2011;37(11):1550-1552. doi:10.1016/j.joen.2011. 08.014

17. Kishen A, Shi Z, Shrestha A, Neoh KG. An investigation on the antibacterial and antibiofilm efficacy of cationic nanoparticulates for root canal disinfection. $J$ Endod. 2008;34(12):1515-1520. doi:10. 1016/j.joen.2008.08.035

18. Lotfi M, Vosoughhosseini S, Ranjkesh B, Khani S, Saghiri M, Zand V. Antimicrobial efficacy of nanosilver, sodium hypochlorite and chlorhexidine gluconate against Enterococcus faecalis. Afr J Biotechnol. 2011;10(35):6799-6803.
19. Chan EL, Zhang C, Cheung GS. Cytotoxicity of a novel nano-silver particle endodontic irrigant. Clin Cosmet Investig Dent. 2015;7:65-74. doi:10.2147/CCIDE.S68874

20. Heravi F, Ramezani M, Poosti M, Hosseini M, Shajiei A, Ahrari F. In vitro cytotoxicity assessment of an orthodontic composite containing titanium-dioxide nano-particles. $J$ Dent Res Dent Clin Dent Prospects. 2013;7(4):192-198. doi:10.5681/joddd.2013.031

21. Besinis A, De Peralta T, Handy RD. The antibacterial effects of silver, titanium dioxide and silica dioxide nanoparticles compared to the dental disinfectant chlorhexidine on Streptococcus mutans using a suite of bioassays. Nanotoxicology. 2014;8(1):1-16. doi:10.3109/17435390. 2012.742935

22. Bryce G, O'Donnell D, Ready D, Ng Y-L, Pratten J, Gulabivala K. Contemporary root canal irrigants are able to disrupt and eradicate single-and dual-species biofilms. J Endod. 2009;35(9):1243-1248. doi:10.1016/j.joen.2009.05.034

23. Haapasalo H, Sirén E, Waltimo T, Orstavik D, Haapasalo M. Inactivation of local root canal medicaments by dentine: an in vitro study. Int Endod J. 2000;33(2):126-131. doi:10.1046/j.1365-2591. 2000.00291.x

24. Lee B-S, Hsieh -T-T, Chi DC-H, Lan W-H, Lin C-P. The role of organic tissue on the punch shear strength of human dentin. $J$ Dent. 2004;32(2):101-107. doi:10.1016/j.jdent.2003.09.001

25. Mohammadi Z, Abbott P. The properties and applications of chlorhexidine in endodontics. Int Endod J. 2009;42(4):288-302. doi:10.1111/j.1365-2591.2008.01540.x

26. Ferraz CCR, de Almeida Gomes BPF, Zaia AA, Teixeira FB, de Souza-filho FJ. In vitro assessment of the antimicrobial action and the mechanical ability of chlorhexidine gel as an endodontic irrigant. $J$ Endod. 2001;27(7):452-455. doi:10.1097/00004770-20010700000004

27. Jowkar Z, Farpour N, Koohpeima F, Mokhtari M, Shafiei F. Effect of silver nanoparticles, zinc oxide nanoparticles and titanium dioxide nanoparticles on microshear bond strength to enamel and dentin. J Contemp Dent Pract. 2018;19(11):1404-1411.

28. Jowkar Z, Omidi Y, Shafiei F. The effect of silver nanoparticles, zinc oxide nanoparticles, and titanium dioxide nanoparticles on the push-out bond strength of fiber posts. J Clin Exp Dent. 2020;12(3): e249-e256. doi:10.4317/jced.56126

29. Tian X, Jiang X, Welch C, et al. Bactericidal effects of silver nanoparticles on lactobacilli and the underlying mechanism. ACS Appl Mater Interfaces. 2018;10(10):8443-8450. doi:10.1021/acsami.7b17274

30. Rai M, Deshmukh S, Ingle A, Gade A. Silver nanoparticles: the powerful nanoweapon against multidrug-resistant bacteria. $J$ Appl Microbiol. 2012;112(5):841-852. doi:10.1111/j.1365-2672.2012.05253.x

31. Gomes-Filho JE, Silva FO, Watanabe S, et al. Tissue reaction to silver nanoparticles dispersion as an alternative irrigating solution. J Endod. 2010;36(10):1698-1702. doi:10.1016/j.joen.2010.07.007

32. Panpaliya NP, Dahake PT, Kale YJ, et al. In vitro evaluation of antimicrobial property of silver nanoparticles and chlorhexidine against five different oral pathogenic bacteria. Saudi Dent J. 2019;31(1):76-83. doi:10.1016/j.sdentj.2018.10.004

33. Nagendrababu V, Meiyazhagan G, Beaula WS, et al. Comparison of the antibacterial efficacy of silver nanoparticles with chlorhexidine against enterococcus faecalis biofilm - an in vitro study. $J$ Nanosci Nanotechnol. 2017;17(7):4613-4617. doi:10.1166/jnn.2017.13711

34. Sharma V, Shukla RK, Saxena N, Parmar D, Das M, Dhawan A. DNA damaging potential of zinc oxide nanoparticles in human epidermal cells. Toxicol Lett. 2009;185(3):211-218. doi:10.1016/j.toxlet. 2009.01.008

35. Osorio R, Yamauti M, Osorio E, Román JS, Toledano M. Zinc-doped dentin adhesive for collagen protection at the hybrid layer. Eur J Oral Sci. 2011;119(5):401-410. doi:10.1111/j.1600-0722.2011.00853.x

36. Shrestha A, Zhilong S, Gee NK, Kishen A. Nanoparticulates for antibiofilm treatment and effect of aging on its antibacterial activity. J Endod. 2010;36(6):1030-1035. doi:10.1016/j.joen.2010.02.008 
37. Cao B, Wang Y, Li N, Liu B, Zhang Y. Preparation of an orthodontic bracket coated with an nitrogen-doped TiO2-xNy thin film and examination of its antimicrobial performance. Dent Mater J. 2013;32(2):311-316. doi:10.4012/dmj.2012-155

38. Shrestha A, Fong S-W, Khoo B-C, Kishen A. Delivery of antibacterial nanoparticles into dentinal tubules using high-intensity focused ultrasound. J Endod. 2009;35(7):1028-1033. doi:10.1016/j.joen. 2009.04.015

39. Vilanova W, Carvalho-Junior J, Alfredo E, Sousa-Neto M, SilvaSousa Y. Effect of intracanal irrigants on the bond strength of epoxy resin-based and methacrylate resin-based sealers to root canal walls. Int Endod J. 2012;45(1):42-48. doi:10.1111/j.13652591.2011.01945.x

40. de Almeida J, Hoogenkamp M, Felippe WT, Crielaard W, van der Waal SV. Effectiveness of EDTA and modified salt solution to detach and kill cells from Enterococcus faecalis biofilm. J Endod. 2016;42 (2):320-323. doi:10.1016/j.joen.2015.11.017

41. Tay FR, Gutmann JL, Pashley DH. Microporous, demineralized collagen matrices in intact radicular dentin created by commonly used calcium-depleting endodontic irrigants. J Endod. 2007;33 (9):1086-1090. doi:10.1016/j.joen.2007.04.017
42. Saleh IM, Ruyter IE, Haapasalo M, Orstavik D. The effects of dentine pretreatment on the adhesion of root-canal sealers. Int Endod J. 2002;35 (10):859-866. doi:10.1046/j.1365-2591.2002.00585.x

43. Pashley DH, Tay FR, Carvalho RM, et al. From dry bonding to water-wet bonding to ethanol-wet bonding. A review of the interactions between dentin matrix and solvated resins using a macromodel of the hybrid layer. Am J Dent. 2007;20(1):7-20.

44. Li X, Cui R, Liu W, et al. The use of nanoscaled fibers or tubes to improve biocompatibility and bioactivity of biomedical materials. J Nanomater. 2013;2013:1-17.

45. Mandava J, Chang PC, Roopesh B, Faruddin MG, Anupreeta A, Uma C. Comparative evaluation of fracture resistance of root dentin to resin sealers and a MTA sealer: an in vitro study. J Conserv Dent. 2014;17(1):53-56. doi:10.4103/0972-0707.124140

46. Neal AL. What can be inferred from bacterium-nanoparticle interactions about the potential consequences of environmental exposure to nanoparticles? Ecotoxicology. 2008;17(5):362-371. doi:10.1007/ s10646-008-0217-x

47. Tamse A. Vertical root fractures in endodontically treated teeth: diagnostic signs and clinical management. Endod Topics. 2006;13 (1):84-94. doi:10.1111/j.1601-1546.2006.00200.x

\section{Publish your work in this journal}

Clinical, Cosmetic and Investigational Dentistry is an international, peer-reviewed, open access, online journal focusing on the latest clinical and experimental research in dentistry with specific emphasis on cosmetic interventions. Innovative developments in dental materials, techniques and devices that improve outcomes and patient satisfaction and preference will be highlighted. The manuscript management system is completely online and includes a very quick and fair peer-review system, which is all easy to use. Visit http://www.dovepress.com/testimonials.php to read real quotes from published authors 